\title{
Capillaria hepatica-induced hepatic fibrosis in rats: paradoxical effect of repeated infections
}

\author{
Fibrose do fígado e Capillaria hepatica em ratos: \\ efeito paradoxal nas infecções repetidas
}

\author{
Ludmila Oliveira ${ }^{1}$, Márcia Maria de Souza ${ }^{2}$ and Zilton A. Andrade ${ }^{3}$
}

\begin{abstract}
Multiple exposures to parasitic agents are considered an important factor in the genesis of the most severe forms of the diseases they cause. Capillaria hepatica-induced septal fibrosis of the liver in rats usually runs without signs of portal hypertension or hepatic failure. After determining the hepatic profile of 15 animals during the course of a single infection, we submitted 20 rats to multiple Capillaria hepatica infections to determine whether repeated exposures would augment fibrosis production, transforming septal hepatic fibrosis into a true cirrhosis. Ten single-infection rats served as controls. A total of 5 exposures, with 45-day intervals, were made. Histological changes were followed by means of surgical liver biopsies, collected prior to infection and to each re-infection. Functional changes were minimal and transient. Although a slight recrudescence of fibrosis was observed after the first two re-infections and when the single-infected control group was re-infected at the end of the experiment, subsequent re-infections failed to increase the amount of fibrosis. On the contrary, there occurred quantitative and qualitative evidence of collagen degradation and suppression of parasite development. These paradoxical results are in keeping with the hypothesis that a complex immunological modulation participates in the mechanism of hepatic fibrosis induced by Capillaria hepatica infection in rats.
\end{abstract}

Key-words: Capillaria hepatica. Hepatic fibrosis. Repeated infections.

\section{RESUM0}

As infecções repetidas são consideradas um importante fator na patogenia das formas mais graves das doenças causadas por parasitos. Afibrose da hepatopatia causada por Capillaria hepatica em ratos cursa na ausência de sinais de hipertensão porta ou insuficiência hepática. Depois de determinar o perfil hepático em 15 animais durante o curso de uma infecção, submetemos 20 outros ratos a infecções repetidas, numa tentativa para produzir formas mais graves, com excesso de fibrose e evolução para a cirrose. Ao todo foram feitas cinco infecções, com intervalo de 45 dias entre as mesmas. As alterações foram seguidas através biópsias hepáticas tomadas antes da infecção e de cada re-infecção. Um grupo controle, com infecção simples foi usado para comparação. As alterações funcionais foram mínimas e transitórias. Embora tenha sido notado um ligeiro aumento da fibrose na $2^{\text {a }}$ e $3^{\text {a }}$ re-infecções ou quando o grupo controle foi re-infectado ao término do experimento, as infecções repetidas não causaram aumento da fibrose. Pelo contrário, foram observados sinais de degradação da fibrose e de interferência com o desenvolvimento parasitário. Estes resultados paradoxais apóiam a sugestão de que um complexo mecanismo de modulação imunológica está envolvido na produção da fibrose hepática induzida pela Capillaria hepática em ratos.

Palavras-chaves: Capillaria hepatica. Fibrose hepática. Infecções repetidas.

Septal fibrosis of the liver regularly appears in rats infected with the helminth Capillaria hepatica ${ }^{8}$. The worms mature exclusively inside the liver and die and disintegrate soon after egg laying in rats. This occurs by the $20^{\text {th }}-25^{\text {th }}$ day after inoculation. Dead worms and their eggs cause focal necrosis and inflammation within the liver. By the time septal fibrosis starts to appear following the first infection, parasite-induced focal necro-inflammatorylesions are undergoing encapsulation

1. PIBIC Student ( CNPq/UFBA) . 2. Master in Pathology - FIOCRUZ/UFBA. 3. Head, Laboratory of Experimental Pathology, Gonçalo Moniz Research Center, FlOCRUZ, Bahia.

Supported by PAPES III, Oswaldo Cruz Foundation and PIBIC ( CNPq/UFBA).

Address to: Dr. Zilton A. Andrade. Centro de Pesquisas Gonçalo Moniz/FIOCRUZ. Rua Valdemar Falcão 121, 40295-001 Salvador, BA, Brazil.

e-mail: zilton@ cpqgm.fiocruz.br

Recebido para publicação em 28/11/2003

Aceito em 13/2/2004 
and resorption ${ }^{816}$. Although the dead-worm lesions tend to disappear, septal fibrosis seems progressive, at least during the first two-three months after infection ${ }^{8}$. Soon its fine and long fibrous septa involve the whole liver parenchyma, connecting portal space to portal space, and eventually to central veins, creating a mosaic pattern of pseudo-lobules that resembles secondary biliary cirrhosis. However, this morphological picture is associated neither with signs of progressive disease nor with evidence of portal hypertension or hepatic failure. Indeed the functional counterpart of the C. hepatica model needs to be better investigated.

Shibayama and Nakata ${ }^{15}$ demonstrated that rats with septal hepatic fibrosis induced by repeated intraperitoneal injections of pig serum presented portal pressure, oxygen consumption and liver weight comparable to normal controls. They concluded that the simple presence of hepatic fibrosis does notnecessarily alter circulatory dynamics and hepatocellular function. Although C. hepatica-induced septal fibrosis presents similar intensity and distribution as that found in the pig-serum model, one should consider that in the former there are in addition the focal lesions produced by dead or dying parasites, and their eggs.

The present investigation has a two-fold objective: to perform a preliminary and general study of the hepatic function in correlation with the formation and evolution of $\mathrm{C}$. hepaticainduced septal fibrosis in rats; and to determine whether multiple exposure to C. hepatica infection would result in an aggravation of the lesions, and the production of a true parasitic cirrhosis.

\section{MATERIALS AND METHODS}

Animals. Young adult Wistar rats of both sexes, weighing $150-200 \mathrm{~g}$, maintained in good and controlled housing conditions of humidity and temperature, with free access to water and to a pellet-balanced commercial diet were used throughout the experiments.

Inoculum. Consisted of embryonated eggs of $\mathrm{C}$. hepatica administered by means of a gastric tube. The eggs were obtained from the livers of experimentally infected mice. These organs were added to a small quantityof tap water and homogenized in an electric blender at 1,000 rpm/3min, followed by washing and decantation. The clean immature eggs obtained were leftin a humidified Petri dish for 28-30 days, at $26-28^{\circ} \mathrm{C}$ to embryonate, when they were counted in a microscope and used. More details regarding the obtaining, preparation and counting of the inoculum are described elsewhere ${ }^{81016}$. The amount of eggs in the inoculum varied in different experiments, but thathas been demonstrated not to interfere with the results as far as septal fibrosis is concerned ${ }^{12}$.

Determination of the hepatic functional profile. A group of 15 rats were infected with 600 embryonated C. hepatica eggs. Tail vein blood was collected from all animals. Sera taken from pre-infected animals (Controls) and 43 and 76 days after infection were submitted to biochemical analysis for aminotransferases ( ALT and AST) , alkaline phosphatase, gammaglutamyl-transpeptidase ( G-GT), total and direct bilirubin, and albumin by means of an automatic analyzer Hitachi 917 at the Bahia State Central Laboratory ( LACEN).
Repeated infections. Twenty animals were submitted to five infections, each with 100 embryonated eggs at 45-day intervals, totaling one infection and four re-infections. At the time the animals were being submitted to the $5^{\text {th }}$ infection, it was decided that the remaining 3 animals from the $1^{\text {st }}$ Group ( single-infection controls), should also be re-infected, since their response, after a prolonged interval from first infection, appeared to be of interest.

Single-infection. Ten animals were submitted to an infection with 100 embryonated C. hepatica eggs and received no further inoculation, these were followed in all other procedures as controls.

Specimens collected. Fragments of the liver were collected by surgical biopsy from all animals at 45 days from the last inoculation. In addition, one animal from the single-infection group and three from the repeated-infection group were sacrificed at each experimental period. The liver fragments obtained either by biopsy or autopsy were fixed in $10 \%$ neutral formalin, embedded in paraffin and the blocks cut in a microtome at 5-10 micrometers. The sections were stained with hematoxylin and eosin, and with the Sirius-red method for collagen.

Evaluation of fibrosis. 1. Hydroxyproline determination: biochemical determination of hydroxyproline content was made according to the colorimetric method of Bergman \& Loxley².

2. Semi-quantitative analysis: fibrosis was semiquantitatively evaluated under the microscope, by two independent observers unaware of the respective protocols, from Sirius-red stained slides as minimal $(+)$, moderate $(++)$ and marked $(+++)$. These degrees represented, respectively: $(+)$ whether septal fibrosis appeared in a few focal areas, usually at the proximity of parasitic lesions, leaving most of the liver parenchyma uninvolved; $(++)$ fibrosis observed throughout the liver, but with very thin septa, largely separated one from the other, and some of them incomplete; $(+++)$ prominent and larger septa, thoroughly distributed within the liver. No case of absence of fibrosis was found in any examined section.

Serum antibodies. Sera were collected at sacrifice and submitted to an ELISA test for detection of total Ig anti-C. hepatica antibodies, by using a goat anti-rat IgG conjugated to peroxidase ( Sigma, Saint Louis, MO, USA). The plates were sensitized with $10 \mu \mathrm{g} / \mathrm{ml} /$ per well of C. hepatica-egg and worm antigen, diluted in carbonate buffer, pH 9.6 Reading was done using a microplate reader Molecular devicesThermomax spectrophotometer ( Sunyvaley, CA, USA) under wavelength $450 \mathrm{~nm}$, connected to a computer running MDSSoft Max.

Statistical analysis. The numerical analysis of the serum antibody levels obtained by the ELISA test, and those derived from the biochemical measurements of hydroxyproline was made by the Student-Newman-Keuls one-way-ANOVA.

\section{RESULTS}

The results of the tests to evaluate the hepatic profile of normal and C. hepatica-infected rats, during two different periods of infection, are given in Table 1. They revealed that the 
Table 1 - Hepatic functional profile in Capillaria hepática-infected rats.

\begin{tabular}{lccc}
\hline Test & $\begin{array}{c}\text { Controls } \\
(\mathrm{N}=5)\end{array}$ & $\begin{array}{c}\text { INF. 43 Days } \\
(\mathrm{N}=5)\end{array}$ & $\begin{array}{c}\text { INF. 76 Days } \\
(\mathrm{N}=9)\end{array}$ \\
\hline Total Proteins & $6,7 \pm 0,3$ & $6,9 \pm 0,3$ & $6,6 \pm 0,3$ \\
Albumin & $4,1 \pm 0,2$ & $4,0 \pm 0,1$ & $4,3 \pm 0,2$ \\
TGO (AST) & $140,8 \pm 7,8$ & $162,2 \pm 35,2$ & $150,0 \pm 32,2$ \\
TGP (ALT) & $68,4 \pm 14,7$ & $92,2 \pm 22,4$ & $58,0 \pm 4,7$ \\
Gamma-GT & $5,8 \pm 2,6$ & $4,2 \pm 0,8$ & $5,0 \pm 0,3$ \\
Alkaline phosphatase & $139,4 \pm 43,2$ & $367,6 \pm 50,8$ & $109,8 \pm 25,4$ \\
Total bilirubin & $0,3 \pm 0,1$ & $0,2 \pm 0,1$ & $0,3 \pm 0,1$ \\
Direct bilirubin & $0,1 \pm 0,1$ & $0,1 \pm 0,0$ & $0,1 \pm 0,0$ \\
\hline
\end{tabular}

infection did not cause much deviation from normal, except for a slight increase in alkaline phosphatase and aminotransferase levels during the $45^{\text {th }}$ day of infection, a moment when focal necro-inflammatory parasitic lesions are prominent.

Quantitative data on fibrosis, as revealed by measurement of hydroxyproline content, are presented in Figure 1. They revealed that repeated infection with $\mathrm{C}$. hepatica did not result in significant increase of liver fibrosis. There was a slight increase following a second infection, especially when animals with long-duration single infection ( controls) were re-infected

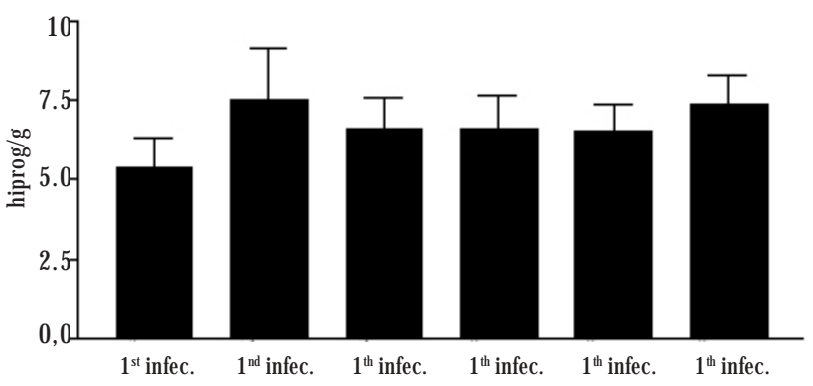

Figura 1 - Hydroxiproline measurements in rat livers following single and repeated infections with Capillaria hepatica $p>0.05$.

at the time the others were receiving their $5^{\text {th }}$ inoculation. The semi-quantitative analysis of histological picro-sirius stained slides yielded similar results. Search for anti-C. hepatica serum antibodies revealed progressively increased levels during repeated inoculations ( Figure 2). Single-infected animals that were re-infected later, at the time of the $5^{\text {th }}$ re-infection, showed a significant increase in hydroxyproline measurements, without increase in serum-antibody levels.

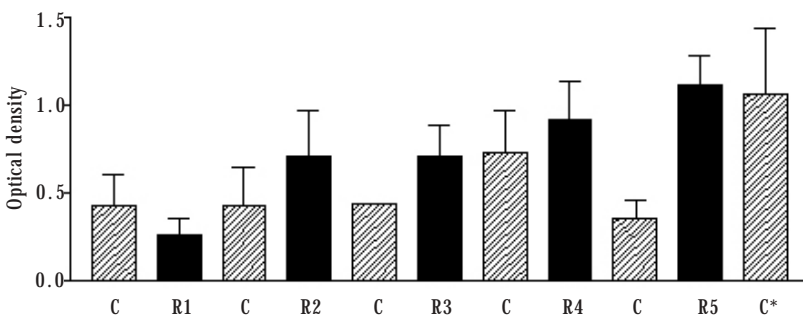

*Represents control single-infected rats that were re-infected 8 mounths later.

Figure 2 - Anti-Capillaria hepatica serum antibody levels in rats, evaluated with 45-days intervals, in single-infected animals ( $\mathrm{C}$ ) and in successifully re-infected ones (R). $p<0.05$.
The livers of all the animals, microscopically examined on the $45^{\text {th }}$ day of infection, showed a uniform picture of focal parasite-derived inflammatory lesions and septal fibrosis. The focal lesions were encapsulated and contained necrotic adult worms and eggs, in and around them, mixed with a rich cellular exudate (Figure 3A) . Fibrous septa were seen around the focal parasitic lesions and distant from them, usually connecting portal spaces to another portal space. The amount of fibrosis was variable from case to case.

Forty-five days later, these main findings continued without significant modifications. The parasitic lesions became smaller than before; most of the central parasitic debris had been removed, leaving clusters of parasite eggs in its place. Calcification was present in some parasitic foci. These lesions were similarly found both in the animals with single or two infections. Septal fibrosis was evident throughout the liver, and more marked in the reinfected animals.

Around the $120^{\text {th }}$ day from the first inoculation, a notable difference was found regarding the focal parasitic lesions seen in the animals submitted to three repeated infections and the single-infected controls. While the remnants of the worms almost disappeared from the focal lesions in the latter, collections of live immature worms were found in the former (Figure 3B). Some more developed worms presented a few eggs, delimited
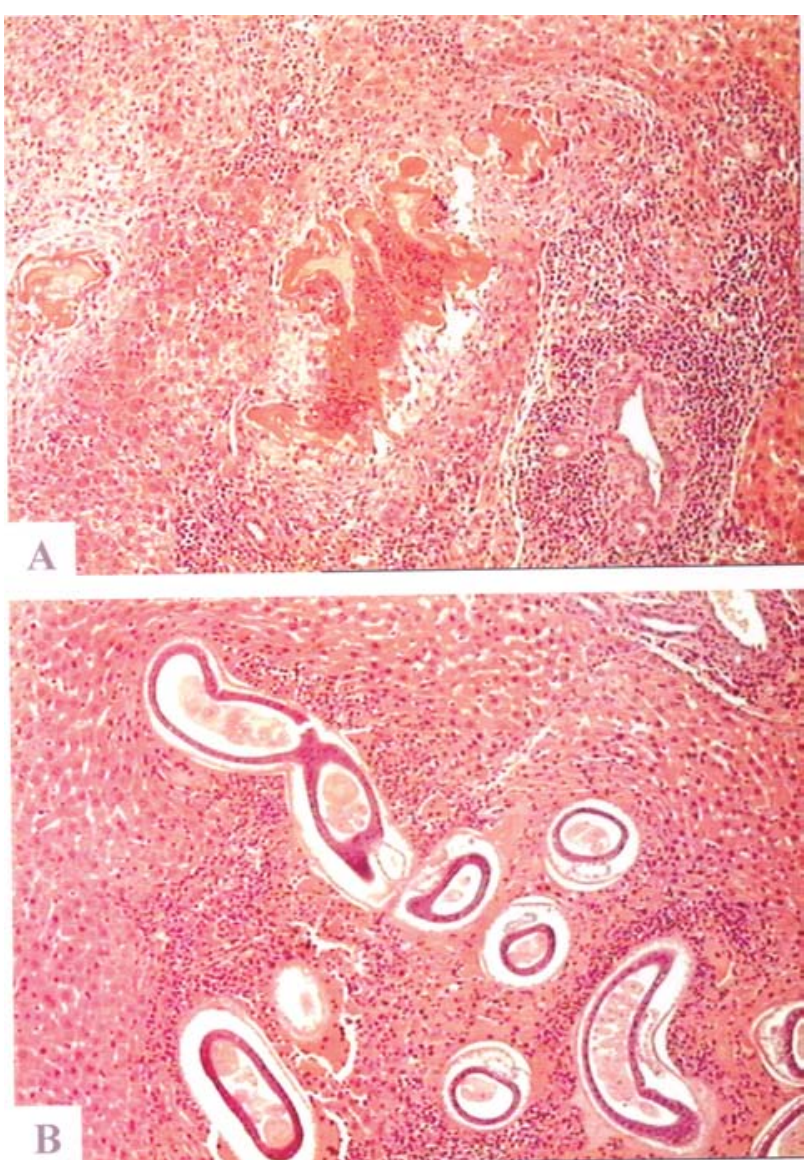

Figure 3 - A) Necrotic worms surrounded by a capsule of macrophages mixed with lymphocytes, located near a portal space, which shows concentration of mononuclear leukocytes around a bile duct. $\mathrm{H} \& \mathrm{E}, 100 \mathrm{X}$. B) A collection of live immature worms within a necro-inflamatory area appears in the liver parenchyma of a rat, 45 days after the $3^{\text {rd }}$ re-infection and 120 days from the first infection. $\mathrm{H} \& \mathrm{E}, 100 \mathrm{X}$ 
by thin and transparent shells, located both within and around their bodies. Fibrous septa present in both groups became very thin and frequently interrupted or fragmented, exhibiting a wavy pattern instead of the previous straight one. From then on, these features just described became more and more evident. Fewer and fewer, dead and live immature worms appeared in the focal lesions from the animals submitted to re-infections. Non-specific inflammatory reactions were minimal around them. Septal fibrosis became residual. Involutive lesions were also observed in animals submitted to single infection. Parasite eggs appeared concentrated in focal collections within the liver. Focal lesions were atrophic and calcified ( Figure 4). Septal fibrosis was less and less evident, but was present as thin and long septa, sometimes more evident than that observed in repeatedly infected animals. This regressive histological picture appeared to be stabilized from around the $4^{\text {th }}$ month on ( Figure 5).
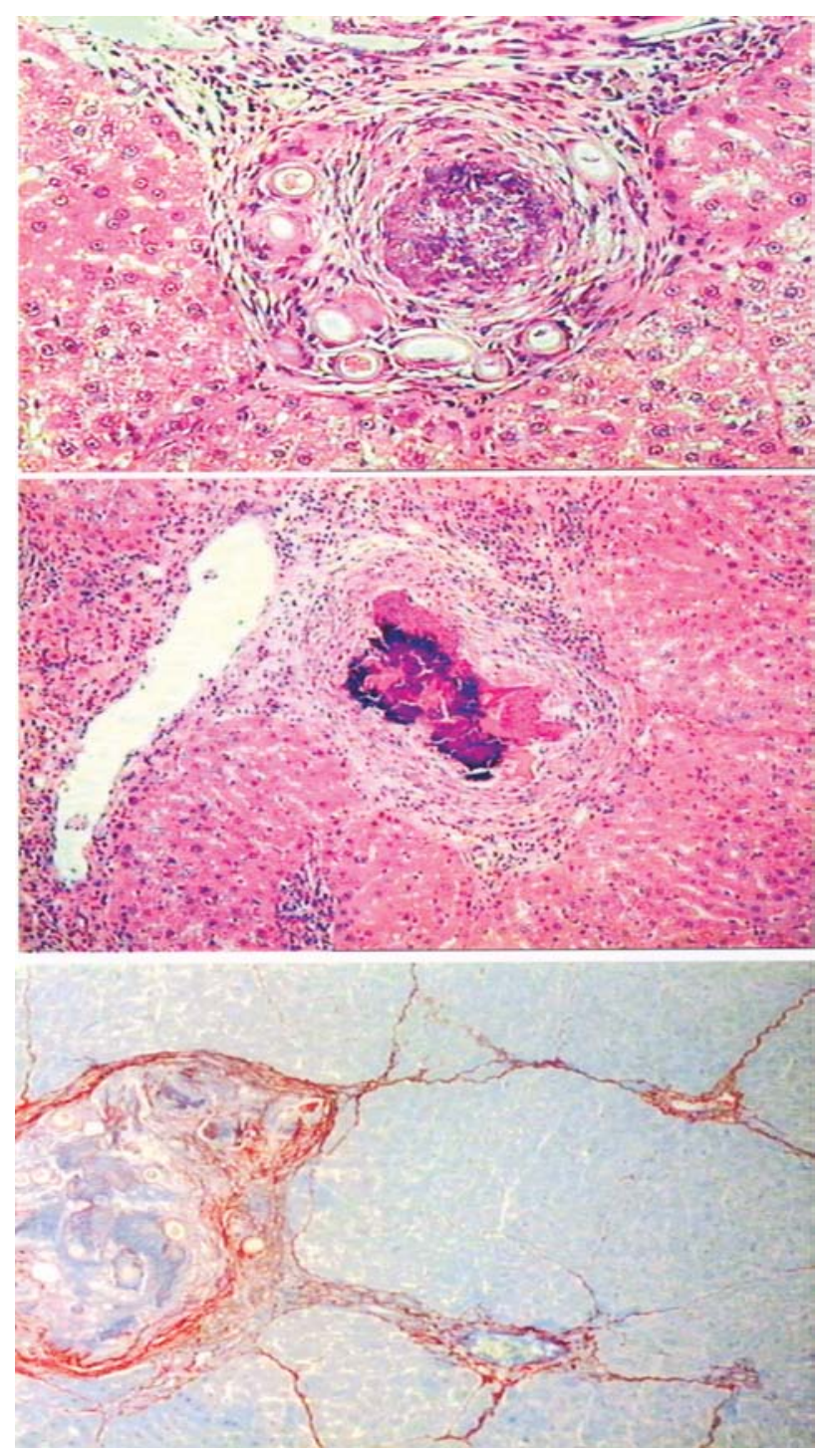

Figure 4 - Involutive focal parasitic lesions. Top and middle pictures illustrate the shrunken, calcified and encapsulated focal lesions caused by dead parasites and eggs in the liver of rats, in spite of repeated infections with Capillria hepatica. H \& E, 200X. The picture at bottom shows involutive changes both in focal parasitic lesion and in septal fibrosis present in the liver of a rat after 3 re-infections with Capillaria hepatica. Sirius-red for collagen, 100X.
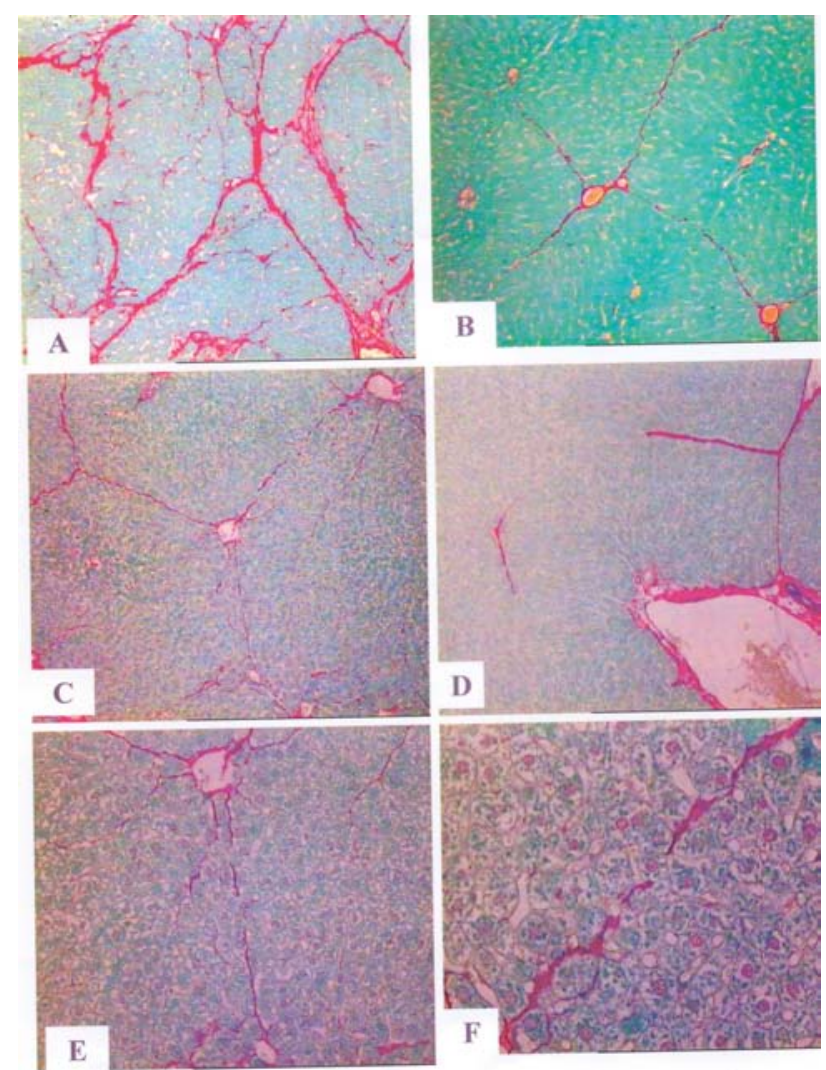

Figure 5 - A) septal fibrosis of the liver in a rat 45 days after a first infection. Fibrous septa appear prominent, connecting portal spaces. B to F) illustrates degradative changes of fibrous septa appearing from the $4^{\text {th }}$ reinfection on and consisting in thinning and fragmentation of the collagen bands. Sirius-red for collagen. 100X, except F (200X).

\section{DISCUSSION}

Capillaria hepatica infection is well tolerated in rats. The association with diffuse septal fibrosis does not signify a major impact on hepatic function, the profile of which changes very little during the course of infection. In this question, our findings confirm those of Shibayana and Nakata observed in septal fibrosis induced by pig-serum ${ }^{15}$.

Re-exposure to infection is supposedly an important event in the development of the most severe forms of parasitic diseases. The decrease in mortality and in morbidity which has been observed following the official campaign for Triatoma infestans eradication in endemic areas of Chagas' disease, indirectly points toward the importance of re-exposure to infection as an aggravating factor in the pathogenesis of parasitic disease $e^{7}$. The importance of re-infection in aggravating the clinicopathological course of parasitic diseases has been demonstrated for schistosomiasis. The development of hepatosplenic disease, with its accompanying periportal fibrosis and intra-hepatic vascular obstruction rarely occurs in infected patients migrating away from an endemic area ${ }^{6}$. Transmission control in an isolated endemic area of the state of Bahia, Brazil, was followed by amelioration of clinical manifestations and by suppression of hepatosplenic disease development ${ }^{4}$. Experimentally, periovular granulomas are larger ${ }^{5}$ and periportal fibrosis more 
frequent in mice subjected to repeated schistosomal infections ${ }^{14}$. In cases of intestinal helminthiasis the severity of the clinical repercussions is usually directly related to worm load. Of course it may be the result of a heavy primary infection, but in many cases multiple re-infections can be implicated (Ascaris, Ancylostoma, and even Trichuris). The cycle of autoinfection in Strongyloids stercoralis infection, by increasing the worm burden, is the basis of the severest cases of this helminthiasis observed in $\operatorname{man}^{1}$. Therefore, the situation of C. hepatica observed in the present study makes a striking exception. The immunology of $\mathrm{C}$. hepatica infection has been little investigated, especially concerning the problems related to re-infections ${ }^{917}$. Most of the cases observed in humans have been characterized by heavy worm burden, probably due to a massive first infection ${ }^{13}$, but similar events have not been described in cases observed in natural infections of animals ${ }^{917}$. But, if the data on susceptibility and resistance of rats to C. hepatica infection are few, much less is known about the influence of immunological factors in relation to the pathogenesis of the associated septal hepatic fibrosis. Septal fibrosis induced by pig-serum was considered to have an immunological basis, because it did not form in animals rendered tolerant to pig-serum ${ }^{3}$. Similar results were obtained for the C. hepatica-induced septal fibrosis by Lemos et al ${ }^{11}$. However, the mechanisms of fibrosis production, the immunological factors involved, have not yet been determined. It seems that such mechanisms run parallel with the ability of the host to destroy the parasites. Our present findings suggest that both the capacity to mount destructive lesions against the parasites and the ability to produce septal fibrosis can be blocked by an excess of worm-derived antigens occurring during repeated infections. Apparently humoral factors ( serum antibodies against C. hepatica) are not involved, unless they acted in a negative way, since their concentration increased in the serum during re-infections. The morphological findings now observed are strikingly similar to those in rats made tolerant to $\mathrm{C}$. hepatica by neonatal contact with the homologous antigens, as described by Lemos et a ${ }^{11}$. In both cases there occurred interference with worm development and a marked decrease in inflammation and fibrosis. It is hoped that these findings will contribute to calling attention to the immunological nature of $\mathrm{C}$. hepatica-induced septal fibrosis in rats and thereby stimulate further studies to clarify its mechanisms.

\section{REFERENCES}

1. Andrade ZA, Gomes MC. Pathology of fatal strongyloidiasis. Revista do Instituto de Medicina Tropical de São Paulo 6: 28-34, 1964.

2. Bergman I, Loxley R. Two improved and simplified methods for the spectrometric determination of hydroxyproline. Analytical Chemistry 35 : 1961-1965, 1963.

3. Bhunchet E, Eishi $Y$, Wake K. Contribution of immune response to the hepatic fibrosis induced by porcine serum. Hepatology 23: 811-817, 1996.

4. Bina JC. Estudo de variáveis que podem influenciar na evolução da esquistossomose mansônica: efeito da terapêutica específica e da interrupção do tratamento. Tese de Doutorado. Universidade Federal da Bahia, Salvador, 1995.

5. Coelho PM, Toppa NH, Mello RT, Feldman JS, Gonçalves R. Schistosoma mansoni: exacerbation of inflammatory granulomatous response in mice chronically infected and submitted to reinfection. Revista do Instituto de Medicina Tropical de São Paulo 38:303-305, 1996.

6. Coura JR. Follow up of patients with schistosomiasis living in non-endemic area in Brazil. Brasília-Médica 2: 45-47, 1975.

7. Dias JC, Silveira AC, Schofield CJ. The impact of Chagas' disease control in Latin America - A Review. Memórias do Instituto Oswaldo Cruz 97: 603$612,2002$.

8. Ferreira LA, Andrade ZA. Capillaria hepatica: a cause of septal fibrosis of the liver. Memórias do Instituto Oswaldo Cruz 88: 411-447, 1993.

9. Galvão VA. Estudo sobre Capillaria hepatica: uma avaliação do seu papel patogênico para o homem. Memórias do Instituto Oswaldo Cruz 76: 415433, 1981.

10. Gotardo BM, Andrade RG, Andrade ZA. Hepatic pathology in Capillaria hepatica infected rats. Revista da Sociedade Brasileira de Medicina Tropical 33: 341-346, 2000.

11. Lemos QT, Magalhães-Santos IF, Andrade ZA. Immunological basis of septal fibrosis of the liver in Capillaria hepatica-infected rats. Brazilian Journal of Medical and Biological Research 36: 1201-1207, 2003.

12. Oliveira RF, Andrade ZA. Worm load and septal fibrosis of the liver in Capillaria hepatica-infected rats. Memórias do Instituto Oswaldo Cruz 96: 1001-1003, 2001.

13. Piazza R, Correa MA, Fleury RV. Sobre um caso de infestação humana por Capillaria hepatica. Revista do Instituto de Medicina Tropical de São Paulo 5: 37-41, 1963.

14. Santos ABA, Souza MM, Andrade ZA. Reinfecções e desenvolvimento da fibrose periportal esquistossomótica no modelo murino. Revista da Sociedade Brasileira de Medicina Tropical 33: 197-200, 2000.

15. Shibayama Y, Nakata K. Significance of septal fibrosis for disturbances of hepatic circulation. Liver 12: 22-25, 1992.

16. Souza MM, Silva LM, Barbosa Jr AA, Oliveira IR, Paraná R, Andrade ZA. Hepatic capillariasis in rats: a new model to testing antifibrotic drugs. Brazilian Journal of Medical and Biological Research 33: 1329-1334, 2000.

17. Wright KA. Observations on the life cycle of Capillaria hepatica ( Bancroft, 1893) with a description of the adult. Canadian Journal of Zoology 38: 167 182, 1961. 